\title{
Variability in spectral backscatter estimated from satellites and its relation to in situ measurements in optically complex coastal waters
}

\author{
MARK A. MOLINE* ${ }^{*}$, ROBERT ARNONE\$, TRISHA \\ BERGMANN§, SCOTT GLENN§, MATTHEW J. OLIVER $\dagger$, \\ CRISTINA ORRICO $\dagger$, OSCAR SCHOFIELD $\$$ and SASHA TOZZI\$ \\ $\uparrow$ Biological Sciences Department, California Polytechnic State University, \\ San Luis Obispo, CA 93407, USA \\ $\ddagger$ Naval Research Laboratory, Stennis Space Center, MS 39529, USA \\ SInstitute of Marine and Coastal Sciences, Rutgers University, New \\ Brunswick, NJ 08901, USA
}

\begin{abstract}
A large database of in situ bio-optical measurements was collected at the Long-term Ecosystem Observatory off the southern coast of New Jersey, USA. In part, the research effort focused on reconciling in situ estimates with satellite-derived estimates of the inherent optical properties (IOP). At $442 \mathrm{~nm}$, in situ absorption values ranged from less than 0.2 to over 1.5 inverse metres. Satellite estimates of backscatter ranged from 0.002 to 0.03 inverse metres at $442 \mathrm{~nm}$ and showed significant variability in time and space during July 1999 , reflecting the recurrent high frequency events that characterize the region - windmixing, storms and coastal upwelling. Despite this variability, there was good qualitative agreement between the satellite derived IOP estimates and in situ IOP measurements. Both absorption and backscatter values increased near-shore, reflecting enhanced concentrations of phytoplankton, sediments and dissolved organic matter.
\end{abstract}

\section{Introduction}

As part of the Hyperspectral Coastal Ocean Dynamics Experiments (HYCODE), this study had two main objectives: (1) to compare in situ spectral backscatter data with estimated backscatter derived from the Sea viewing Wide Field of view Sensor (SeaWiFS); and (2) to compare in situ spectral scattering data with that modelled from an in situ absorption/attenuation (WetLabs AC-9).

In situ measurements were collected at the Long-term Ecosystem Observatory (LEO-15) off the southern coast of New Jersey, USA using the Hobilabs HydroScat-6 spectral backscatterer. Four of the six wavelengths measured by the HydroScat- 6 are used in this analysis; $442 \mathrm{~nm}, 488 \mathrm{~nm}, 589 \mathrm{~nm}$ and $620 \mathrm{~nm}$, all measured at a $140^{\circ}$ angle. For proper comparison of derived scattering and in situ scattering, a profiling Satlantic spectral radiometer was used to calculate the first 
optical depth. In addition, a WetLabs absorption/attenuation meter (AC-9) was used to quantify the spectral absorption and attenuation through the water column. AC-9 data were used to initialize the radiative transfer model Hydrolight v5.0 to model spectral backscatter. All of these instruments were on the same profiling cage within $20 \mathrm{~cm}$ of each other. Transect lines for three days highlighted in this study are given in figure 1 .

\section{Method}

Spectral backscatter data from the HS-6 was first binned to $0.5 \mathrm{~m}$ depth intervals to eliminate bias due to uneven depth profiling. For comparison to satellite-derived backscatter, the in situ backscatter data were averaged within the first optical depth, which contributes approximately $90 \%$ of the in-water reflectance. Depth-dependent AC-9 data were used for input in the Hydrolight v5.0 model and with backscatter as the output for every $0.5 \mathrm{~m}$ of the water column. The binned HS-6 data were compared to the Hydrolight backscatter at $0.5 \mathrm{~m}$ intervals.

SeaWiFS ocean colour imagery was processed into optical products of spectral absorption and backscattering at all wavelengths (Arnone and Gould 1998) using a modified version of the SeaWiFS Data Analysis System (SEADAS). SeaWiFS image processing was optimized for coastal water using the near-infrared (NIR) atmospheric correction (Arnone et al. 1998). This procedure uses an iterative procedure for coupled in-water and atmospheric models to determine the waterleaving radiance in coastal waters. Coastal waters can have significant reflectance in the $765 \mathrm{~nm}$ and $865 \mathrm{~nm}$ channels of SeaWiFS. The iterative procedure accounts for the water portion of these channels, which are used with atmospheric correction. Accurate reflectance measurements in coastal waters are required for accurate derived optical properties.

These SeaWIFS reflectance measurements are used with two semi-empirical

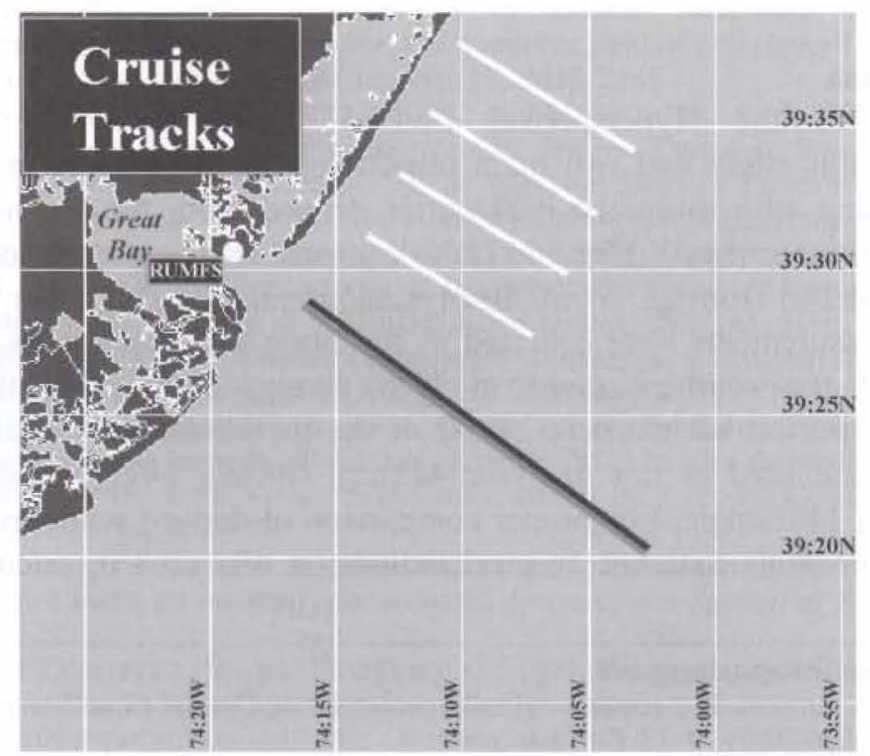

Figure 1. Cruise tracks for three days during July 1999, off the coast of New Jersey in relation to the Rutgers University Marine Field Station. Black line, 7 July; white lines, 16 July; grey line, 30 July. 
in-water algorithms to uncouple the surface water backscatter and absorption properties. These algorithms are based on a reflectance value of ca. 0.33 multiplied by the ratio of backscatter to absorption at a specific wavelength. The modified algorithm determines backscatter at $670 \mathrm{~nm}$ using the reflectance relationship at $670 \mathrm{~nm}$ by assuming a known absorption at $670 \mathrm{~nm}$. Then, using Gould and Arnone (1999), the backscatter is estimated at all wavelengths.

The Carder et al. (1999a, b) algorithm was also used to estimate spectral backscatter. Here the $550 \mathrm{~nm}$ channel is used. This algorithm portioned the total spectral absorption into the absorption from chlorophyll and absorption from dissolved organics and particles. These components were combined with water absorption to estimate the total absorption at each wavelength (Arnone and Gould 1998). The reflectance ratio is then used to convert to spectral backscatter.

SeaWiFS optical properties were compared with in situ optical properties measured using an absorption scattering instrument. The spectral backscatter estimated from SeaWiFS was converted to total scattering using a Petzold volume scattering function (Petzold 1972, Gould et al. 1999). There are limitations with the Petzold conversion, but this study is data limited in coastal waters.

\section{Results}

There was generally good agreement between wavelength-specific measured in situ backscatter and the SeaWiFS derived estimates for both algorithms (table 1). This relationship was robust across several days and stations (figure 2). The SeaWiFS algorithms, however, tended to cluster offshore and inshore waters separately (data not shown), suggesting additional complexity across optical fronts, which characterize the study region. Modelled in situ backscatter derived from the AC-9 also correlated well with measured values at depth; however, this coherence generally broke down in surface waters, illustrating the importance of collecting good surface measurements with the AC-9 in remote sensing applications.

Table 1. Correlation coefficients $\left(\mathrm{R}^{2}\right)$ for measured in situ backscatter and those derived from SeaWiFS.

\begin{tabular}{|c|c|c|c|c|c|c|c|c|c|}
\hline & \multirow[b]{2}{*}{$(\mathrm{nm})$} & \multicolumn{4}{|c|}{$\begin{array}{l}\text { SeaWiFS algorithm } \\
\text { (Arnone et al. 1998) }\end{array}$} & \multicolumn{4}{|c|}{$\begin{array}{l}\text { SeaWiFS algorithm } \\
\text { (Carder et al. 1999a, b) }\end{array}$} \\
\hline & & 443 & 490 & 555 & 670 & 443 & 490 & 555 & 670 \\
\hline \multirow[t]{4}{*}{ Measured 7 July $(n=6)$} & 442 & 0.63 & - & - & - & 0.90 & - & - & - \\
\hline & 488 & - & 0.55 & - & - & - & 0.85 & - & - \\
\hline & 589 & - & - & 0.68 & - & - & - & 0.96 & - \\
\hline & 602 & - & - & - & 0.70 & - & - & - & 0.96 \\
\hline \multirow[t]{4}{*}{ Measured 16 July $(n=12)$} & 442 & 0.57 & - & - & - & 0.57 & - & - & - \\
\hline & 488 & - & 0.64 & - & - & - & 0.63 & - & - \\
\hline & 589 & - & - & 0.67 & - & - & - & 0.69 & - \\
\hline & 602 & - & - & - & 0.69 & - & - & - & 0.74 \\
\hline \multirow{4}{*}{ Measured 30 July $(n=8)$} & 442 & 0.65 & - & - & - & 0.65 & - & - & - \\
\hline & 488 & - & 0.62 & - & - & - & 0.72 & - & - \\
\hline & 589 & - & - & 0.35 & - & - & - & 0.46 & $=$ \\
\hline & 602 & - & - & - & 0.69 & - & - & - & 0.76 \\
\hline
\end{tabular}




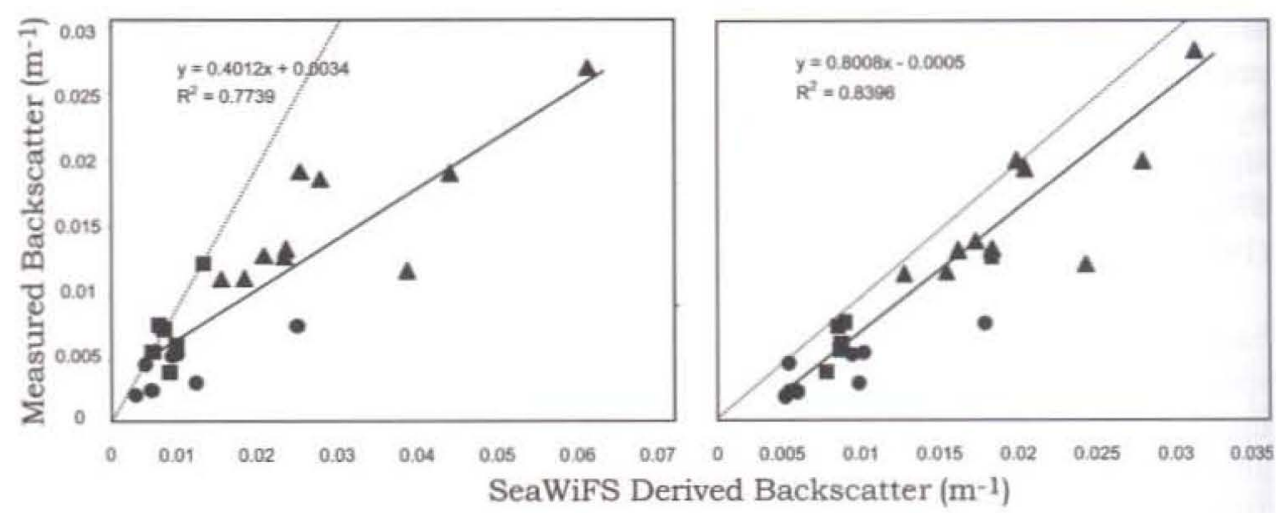

Figure 2. Comparison of optical backscatter derived from SeaWiFS $(490 \mathrm{~nm})$ with that measured in situ $(448 \mathrm{~nm})$. Dotted line shows the 1:1 relationship. Squares, 7 July; triangles, 16 July; circles, 30 July.

\section{Acknowledgments}

We wish to thank Taylor Newton, Erica Peters, Dwight Peterson, the Rutgers Marine Field Station staff and $R / V$ Walford crew for their assistance in collection of data. This study was funded through grants to MAM from NASA (NAG5-8674) and the Office of Naval Research (N00014-99-1-0197).

\section{References}

ARnone, R. A., and Gould, R. W., 1998, Coastal Monitoring Using Ocean Color. Sea Techinology, 39, 18-27.

ARNone, R. A., MARTinolich, P., Gould, R. W. JR., STUmpF, R., and Ladner, S., 1998, Coastal optical properties using SeaWiFS. In Ocean Optics XIV, edited by S. Ackleson (Bellingham, WA: SPIE), pp. 304-312.

CARder, K. L., Chen, F. R., LeE, Z., and HAWES, S., 1999a, MODIS ATBD-19v.5 (Washington D.C.: NASA).

Carder, K. L., Chen, F. R., Lee, Z. P., Hawes, S. K., and Kamykowski, D., 1999b, Semianalytic Moderate-Resolution Imaging Spectrometer algorithms for chlorophyll a and absorption with bio-optical domains based on nitrate-depletion temperatures. Journal of Geophysical Research, 104, 5403-5421.

Gould, R. W., Arnone, R. A., and Martinolich, P. M., 1999, Spectral dependence of the scattering coefficient in case 1 and case 2 waters. Applied Optics, 38, 2377-2383.

PEtzold, T. J., 1972, Volume scattering functions for selected ocean waters. No. Refs. 72-78 (Scripps Institute of Oceanography). 